\title{
Gambaran Klinis Kriptorkismus di Poliklinik Endokrinologi Anak RS Dr. Cipto Mangunkusumo, Jakarta, Tahun 1998 - 2002
}

\author{
Wayan Bikin Suryawan, Jose RL Batubara, Bambang Tridjaja, Aman B Pulungan
}

Latar belakang: kriptorkismus merupakan kelainan organ seksual lelaki yang sering ditemukan. Sampai berapa tahun terapi hormonal dan pembedahan dilakukan masih kontroversial.

Tujuan: penelitian ini bertujuan untuk mengetahui umur saat berobat pertama kali, asal rujukan, lokasi testis, peran perabaan, penyakit penyerta, dan peran terapi hormonal pada kriptorkismus.

Cara kerja: Penelitian dilakukan secara retrospektif dari semua pasien baru yang didiagnosis kriptorkismus di Poliklinik Endokrinologi Anak RSCM selama 5 tahun (Januari 1998 Desember 2002).

Hasil: diteliti 63 pasien baru, 58 pasien diantaranya dengan kriptorkismus murni, dan 5 pasien testis retraktil. Didapat 22,4\% kriptorkismus bilateral, 77,6\% kriptorkismus unilateral, kriptorkismus kanan dan kiri jumlahnya hampir sama. Pasien yang dirujuk oleh spesialis anak $33,3 \%$. Umur pertama datang di poliklinik 9 bulan-2 tahun $24,1 \%$, dan $>2$ tahun $56,9 \%$. Pada perabaan, lokasi testis paling banyak tak teraba $74,1 \%$, setelah dikonfirmasi dengan USG $75 \%$ hasilnya sama dengan perabaan. Kriptorkismus disertai skrotum bifidum dan hipospadia 12,6\%, mikropenis 11,1\%, sindrom Prader Willi, sindrom Noonan, sindrom Kallmann masingmasing 1,6\% dan merupakan penyakit dasar kriptorkismus. Keberhasilan Terapi hormonal $65 \%$ (inguinal $77,8 \%$ dan pada testis tak teraba 50\%), terapi dimulai sejak umur 9 bulan. Kesimpulan: sebagian besar pasien datang pada umur $>2$ tahun, sedangkan terapi hormonal dimulai pada umur 9 bulan dengan keberasilan 65\%. Pemeriksaan fisik sama akurat dibandingkan dengan pemeriksaan USG. Terapi hormonal pada kriptorkismus umur 6 bulan - 2 tahun masih efektif sebelum terapi bedah dilakukan.

Kata kunci: kriptorkismus, perabaan, terapi hormonal HCG

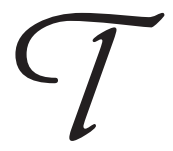

urunnya testis merupakan langkah terakhir dari serangkaian proses genetik, embriologik dan hormonal yang mengatur per-

Dr. Wayan Bikin Suryawan, Sp.A.

RSUD Wangaya, Jln Kartini Denpasar Bali.

Telepon: 0361-222142/222141.

Alamat korespondensi:

Dr. Jose RL Batubara, Sp.A(K).

Subbagian Endokrinologi. Bagian Ilmu Kesehatan Anak FKUI-RSCM. Jl. Salemba no. 6, Jakarta 10430.

Telepon: 021-3100669. Fax.: 021-390 7743. tumbuhan gonad, duktus Wolffian serta diferensiasi dan pertumbuhan genital. Gangguan pada tahap manapun dalam proses ini akan menyebabkan suatu kelainan mulai dari interseksualitas dengan virilisasi berat hingga gangguan penurunan testis sederhana. ${ }^{1}$ Kriptorkismus atau undescended testiscle merupakan kelainan bawaan genital yang paling sering ditemukan ${ }^{2,3,4}$. Insidens kriptorkismus meningkat pada kasus dengan defisiensi gonadotropin, disamping terdapat juga pada beberapa sindrom dengan gangguan biosintesis testosteron. Insidens kriptorkismus pada bayi baru lahir cukup bulan $5,5 \%$, bayi prematur $21 \%$, usia 3 bulan insidennya 
menjadi $1,4 \%$ dan $0,5-0,8 \%$ pada anak usia 1 tahun. ${ }^{2}$ Di RS Dr. Cipto Mangunkusumo Jakarta pada penelitian Darmawan tahun 1997 didapatkan insiden kriptorkismus bayi baru lahir secara keseluruhan 4,2\% dari 2250 bayi yang lahir, dan untuk bayi cukup bulan insiden kriptorkismus 2,2\% dari 2123 bayi cukup bulan, pada bayi kurang bulan insiden kriptorkismus 37\% dari 127 bayi kurang bulan. ${ }^{5}$

Lokasi testis dalam skrotum sangat diperlukan untuk proses spermatogenesis dan fungsi epididemis, karena suhunya yang lebih rendah $1,5-2,0^{\circ} \mathrm{C}$ dibanding suhu tubuh. ${ }^{6}$ Di samping itu testis yang tidak berada pada tempat yang seharusnya mengganggu spermatogenesis dan meningkatkan risiko terjadinya torsi testis dan keganasan ${ }^{1}$. Untuk menghindari kerusakan pada testis terapi hormonal dimulai sebelum usia 2 tahun dan sebaiknya pada usia 6-24 bulan. ${ }^{6,7}$

Dalam penelitian ini akan dilaporkan umur pertama kali datang ke poliklinik endokrinologi anak, asal rujukan, jenis kriptorkismus, lokasi testis, kelainan penyerta, peran pemeriksaan testis manual dibandingkan USG, dan pengelolaan serta peran terapi hormonal.

\section{Metoda Penelitian}

Penelitian ini dilakukan secara retrospektif dengan mengambil data semua pasien baru yang didiagnosis kriptorkismus dan berkunjung ke Poliklinik Endokrin Anak RSCM Jakarta, selama 5 tahun (Januari 1998 Desember 2002). Dicatat pada umur berapa saat datang berobat pertama kali, asal rujukan, jenis kriptokismus, lokasi testis, pemeriksaan penunjang yang digunakan, kelainan penyerta, dan hasil terapi hormonal, yang diambil dari catatan medik.

\section{Batasan Operasional}

Kriptorkismus adalah kelainan genitourinaria ditandai dengan testis tidak turun secara normal ke dalam skrotum. Bila testis kanan tidak turun disebut kriptorkismus kanan, testis kiri tidak turun disebut kriptorkismus kiri, dan kedua testis tidak turun disebut kriptorkismus bilateral. Berdasarkan lokasi dimana teraba, di inguinal, preskrotal, sliding, dan tidak teraba. ${ }^{8}$ Disebut sliding / gliding testis apabila testis teraba di bagian atas skrotum dan bisa ditarik turun tetapi tidak bisa sampai ke dasar dan memerlukan terapi hormonal. Testis ektopik adalah testis turun secara normal di luar salurannya dan berada tidak pada tempatnya. Sedangkan testis retraktil adalah testis turun ke skrotum tapi karena reflek kremaster yang kuat testis tertarik ke atas. ${ }^{8}$ Kelainan penyerta adalah kelainan yang menyertai kriptorkismus dan ada hubungannya dengan kelainan urogenital. Terapi hormonal adalah terapi kriptorkismus dengan injeksi HCG 2x500 IU/minggu selama 5 minggu, terapi hormonal berhasil apabila testis setelah diobati hormonal testis turun dan berada di skrotum.

\section{Hasil Penelitian}

Dari data yang dikumpulkan didapat jumlah pasien baru selama 5 tahun sebanyak 63 pasien, masingmasing untuk tahun 1998, 1999, 2000, 2001 dan 2002 berturut-turut 14, 11, 12, 15 dan 11 orang pasien. Dari 63 pasien yang diteliti, kriptorkismus murni didapatkan pada 58 pasien $(92 \%)$ dan 5 pasien $(8 \%)$ dengan testis retraktil.

Pada 13 pasien kriptorkismus bilateral hanya 8 pasien $(61,5 \%)$ yang dilakukan tes HCG dan semua hasilnya positif.

Dari 63 kasus 32 kasus dikonfirmasi dengan pemeriksaan USG didapatkan hasil 24 kasus (75\%) diagnosis USG sama dengan diagnosis perabaan, 3 dari kasus ditemukan secara perabaan dan dengan USG tidak ditemukan tapi 5 dari kasus dengan USG ditemukan tetapi tidak teraba. Tiga pasien yang hanya dapat dideteksi dengan perabaan adalah seorang pasien mempunyai testis teraba di inguinal kanan, seorang pasien mempunyai testis teraba di inguinal kanan dan kiri, dan seorang pasien mempunyai testis teraba di skrotal kiri. Lima pasien yang hanya dapat dideteksi dengan USG terdiri dari 2 pasien ditemukan testis di inguinal kiri, 2 pasien ditemukan testis di inguinal kanan dan 1 pasien testis di kanalis spermatika dan mengalami obliterasi dan dibantu dengan MRI. Berdasarkan berat badan lahir, $86 \%$ pasien kriptorkismus yang diteliti mempunyai berat badan lahir berkisar antara $2500-4000$ gram, 10\% kurang dari 2500 gram dan 4\% diantaranya mempunyai berat badan lahir lebih dari 4000 gram.

Dari 8 pasien kriptorkismus yang disertai hipospadia dan skrotum bifidum, 3 pasien diperiksa kromosom dan semua hasilnya $46 \mathrm{XY}$. Volume testis kontra lateral kriptorkismus ialah $1 \mathrm{ml}$ : 31,25\%, 1-2 $\mathrm{ml}: 4,1 \%, 2 \mathrm{ml}: 47,9 \%, 2-3 \mathrm{ml}: 4,1 \%, 3 \mathrm{ml}: 8,3 \%$, $4 \mathrm{ml}: 2 \%$, dan $>4 \mathrm{ml}: 2 \%$. Pada penelitian ini 52 
pasien $(82,5 \%)$ mempunyai tinggi badan normal dan 11 pasien $(17,5 \%)$ tinggi badannya di bawah persentil 3 (perawakan pendek).

Dari 20 pasien yang diobati hormonal dengan hasil; 13 pasien berumur antara 9 bulan sampai dengan 2 tahun, 8 pasien diantaranya testis berhasil turun, 7 pasien berumur $>2$ tahun, 2 pasien testis sliding berhasil turun dengan terapi hormonal, 3 dari 5 pasien kriptorkismus testis berhasil turun ke skrotum. Rujukan yang dilakukan; 26 pasien ke Bagian Bedah Anak, 7 pasien ke Bagian Bedah Urologi dan 3 pasien ke Bagian Bedah Plastik.

\section{Diskusi}

Pada pemeriksaan fisik testis retraktil perlu dipisahkan dari UDT karena testis retraktil tidak memerlukan terapi hormonal dan pembedahan. ${ }^{8}$ Kejadian kriptorkismus bilateral $10 \%$ dan unilateral $66 \%$, sedangkan Kleintch dkk mendapatkan 30\% kriptorkismus bilateral dan $70 \%$ kriptorkismus unilateral, ${ }^{9}$ dari kriptorkismus unilateral $70 \%$ kanan, sedangkan insiden kriptorkismus bayi baru lahir cukup bulan 2,7 - 5,9\% dan berkurang menjadi 1,2 - 1,8\% pada umur 1 tahun. Sedangkan pada bayi prematur, insiden meningkat sampai 10 kali. ${ }^{8,9}$ Pada penelitian ini kriptorkismus bilateral sebanyak 22,4\%.

Dari data Poliklinik Endokrin Anak FKUI - RSCM Jakarta, 56,9\% datang pertama kali setelah berumur 2 tahun, sedangkan pada 9 bulan sampai dengan 2 tahun hanya $24,1 \%$ (Tabel 1). Dari haril rujukan terbanyak datang sendiri 44,4\%, dirujuk dokter spesialis anak 33,3 $\%$, dirujuk dokter spesialis bedah anak 9,5\% dan dirujuk dokter umum 4,8\% (Tabel 2). Hal ini menandakan bahwa kriptorkismus sudah dikenal cukup baik oleh masyarakat maupun dokter spesialis anak, hanya mereka belum tahu umur berapa sebaiknya diobati atau sampai umur berapa boleh ditunggu.

Di Poliklinik Endokrin anak FKUI - RSCM, terapi kriptorkismus mulai diberikan apabila pada umur 9 bulan testis belum turun ke skrotum. Diagnosis dan pengobatan kriptorkismus dapat memperbaiki fertilitas dan deteksi dini dari tumor ganas testis, apabila diagnosis dan pengobatan paling baik diberikan antara umur 6 bulan dan sebelum usia 2 tahun. Sebelum umur 6 bulan testis masih dapat ditunggu apabila akan turun spontan,

Tabel 1. Distribusi kriptorkismus berdasarkan umur* dan jenis

\begin{tabular}{lccccc}
\hline Umur & \multicolumn{3}{c}{ Kriptorkismus } & Jumlah & $\%$ \\
\cline { 2 - 4 } & kanan & kiri & bilateral & & \\
\hline$<6$ bl & 4 & 2 & 2 & 8 & 13,8 \\
6 bl $-<9$ bl & 1 & 2 & - & 3 & 5,2 \\
9 bl -2 th & 2 & 8 & 4 & 14 & 24,1 \\
$>2$ th & 16 & 10 & 7 & 33 & 56,9 \\
\hline Jumlah $(\%)$ & $23(39,7)$ & $22(37,9)$ & $13(22,4)$ & $58(100)$ & 100 \\
\hline
\end{tabular}

* Umur pertama kali datang

Tabel 2. Distribusi kriptorkismus berdasarkan asal rujukan

\begin{tabular}{lll}
\hline Asal rujukan & Jumlah & $\%$ \\
\hline Datang sendiri & 28 & 44,4 \\
Dokter Spesialis Anak & 21 & 33,3 \\
Bedah Anak & 6 & 9,5 \\
Dokter Umum & 3 & 4,8 \\
Dokter Kulit Kelamin & 2 & 3,2 \\
Poli Pulmonologi Anak & 1 & 1,6 \\
Poli Neurologi Anak & 1 & 1,6 \\
Poli Bedah Umum & 1 & 1,6 \\
\hline Jumlah & 63 & 100 \\
\hline
\end{tabular}

sedangkan setelah umur 2 tahun meskipun dapat diturunkan tetapi sudah terjadi kerusakan testis sehingga fungsi fertilitas sangat menurun. Empat puluh persen kriptorkismus terjadi kerusakan germ sel dan destruksi tubulus seminiferus, jumlah rata-rata spermatozoa pada kriptorkismus unilateral 0,38 per tubulus, pada kriptorkismus bilateral 0,25 spermatozoa per tubulus sedangkan pada anak normal jumlah 1-1,5 spermatozoa per tubulus. ${ }^{8}$ Penurunan testis dengan terapi hormonal dan pembedahan pada kriptorkismus disarankan mulai umur 6 bulan, supaya tidak terjadi kerusakan testis, yang disebabkan karena suhu dalam skrotum lebih rendah 1$2^{\circ} \mathrm{C}$ daripada intra abdominal. ${ }^{6}$ Pada penelitian ini, 
pasien yang datang pertama kali pada umur 6 bulan sampai dengan 2 tahun hanya $28,1 \%$; berarti perlu diberikan informasi yang lebih luas kepada masyarakat mengenai kapan sebaiknya dirujuk.

Pada perabaan 63 pasien, didapatkan 58 (92\%) menderita kriptorkismus murni, 5 (8\%) dengan testis retraktil, 3 dengan retraktil murni, dan 2 pasien dengan sliding testis, tidak ditemukan testis ektopik (Tabel 3). Dari 58 pasien yang kriptorkismus murni sebagian besar yaitu $74,1 \%$ testis tidak teraba, $24,1 \%$ testis teraba di inguinal dan hanya 1,8\% teraba preskrotal. Kleinteich dkk. Mengatakan bahwa posisi testis terbanyak di inguinal 68\%, preskrotal 24\%, intra abdominal 10\% dan testis ektopik 11,5\%. ${ }^{9}$ Pada pasien yang tidak teraba testisnya kemungkinan terletak intra abdominal atau telah terjadi atrofi testis. ${ }^{9}$ Kasus testis retraktil sering ditemukan, sekitar 20\% dari 600 anak laki-laki umur 12 tahun yang menderita kriptorkismus dan 6\% dari testis retraktil menjadi sliding testis dan bila tidak diobati bisa menjadi kriptorkismus. ${ }^{6}$ Dari 32 pasien yang dilakukan pemeriksaan Ultrasonografi (Tabel 4 dan Tabel 5), 75\% mempunyai diagnosis yang sama dengan yang tak teraba 61\%. Pada penelitian ini akurasinya 75\% dan pengambilan gambar ultrasonografi sebaiknya mengacu rute perjalanan testis. ${ }^{12}$ Konfirmasi diagnosis kriptorkismus yang paling baik saat ini dengan menggunakan laparoskopi untuk testis yang tidak teraba. ${ }^{6}$ Menurut Geraldh dari 5-28\% testis yang tak teraba maksimal $25 \%$ diantaranya tidak ada testis dan $21-40 \%$ testis intra abdominal. ${ }^{13}$

Didapatkan 66,7 \% yang tidak disertai oleh kelainan penyerta dan yang paling banyak adalah hipospadia dengan scrotum bifidum $12,6 \%$ dan, mikropenis $11,1 \%$. Diantara 8 pasien kriptorkismus yang disertai hipospadia dan skrotum bifidum yang diperiksa kromosomnya hanya 3\% (37,5\%), semua didapatkan 46 XY. Sedangkan 5 pasien (62,5\%) tidak diperiksa. Seharusnya semua pasien diperiksa kromosom oleh karena kemungkinan interseksualitas tinggi pada hipospadia dengan kriptorkismus (62\%). ${ }^{8}$ Sindrom yang sering mengikuti ambigous genitalia adalah Kallmann dan, Prader Willi. ${ }^{8}$ Seri kasus kita adalah kriptorkismus diikuti sindrom Prader willi, Kallmann dan Noonan masing-masing 1 orang (Tabel 6).

Tabel 3. Distribusi kriptorkismus berdasarkan lokasi testis

\begin{tabular}{lcccc}
\hline Perabaan & \multicolumn{3}{c}{ Kriptorkismus } & Jumlah \\
\cline { 2 - 5 } & kanan & kiri & bilateral & \\
\hline Tak teraba & 17 & 17 & 9 & 43 \\
Teraba di inguinal & 5 & 5 & 4 & 14 \\
Teraba di preskrotal & 1 & - & - & 1 \\
\hline Jumlah & 23 & 22 & 13 & 58 \\
\hline
\end{tabular}

Tabel 4. Distribusi kriptorkismus berdasarkan hasil USG

\begin{tabular}{lcccc}
\hline Hasil USG & \multicolumn{3}{c}{ Kriptorkismus } & Jumlah \\
\cline { 2 - 4 } & kanan & kiri & Bilateral & \\
\hline Tidak ditemukan testis & 5 & 7 & 7 & 19 \\
Ditemukan testis di inguinal & 5 & 7 & 1 & 13 \\
\hline Jumlah & 10 & 14 & 8 & 32 \\
\hline
\end{tabular}

pemeriksaan perabaan, 9,4\% ditemukan secara perabaan tapi tidak ditemukan dengan ultrasonografi dan 15,6\% ditemukan dengan ultrasonografi tapi tidak ditemukan secara perabaan. Pemeriksaan dengan ultrasonografi jarang dipakai untuk evaluasi kriptorkismus sebab mempunyai akurasi hanya $44 \% .^{6}$ Jack S. Elder ${ }^{11}$ mendapatkan akurasi pemeriksaan ultrasonografi pada
Tabel 5. Distribusi kriptorkismus berdasarkan hasil perabaan dibandingkan dengan pemeriksaan USG

\begin{tabular}{lccc}
\hline Hasil USG & Perabaan $(+)$ & Perabaan $(-)$ & Jumlah \\
\hline USG (+) & 24 & 5 & 29 \\
USG (-) & 3 & 0 & 3 \\
\hline Jumlah & 27 & 5 & 32 \\
\hline
\end{tabular}


Uji HCG dilakukan dengan memberikan suntikan HCG intramuskular tiga hari berturut-turut masingmasing $2000 \mathrm{IU}$, kadar testosteron diperiksa sebelum injeksi dan 24 jam setelah injeksi terakhir. ${ }^{8}$ Diantara 12 pasien kriptorkismus bilateral yang dilakukan uji HCG, hanya 8 pasien $(61,5 \%)$ dari ketujuh pasien dengan uji HCG positif hal ini berarti sel Leydignya masih baik. Didapat 10\% dari kriptorkismus adalah bilateral dan 3-5\% dari bilateral tanpa testis, ${ }^{14}$ Sedangkan 3 pasien $(25 \%)$ dari kriptorkismus bilateral testis tidak ditemukan.

Pada uji HCG perlu dipikirkan kadar FSH dan LH basal untuk mengetahui adanya anorkhia. Pemeriksaan laparoskopi diindikasikan apabila jaringan testis tidak berfungsi atau memperbaiki lokasi dari jaringan testis yang tidak turun. ${ }^{14,15}$

Pada penelitian ini dari 63 pasien yang diteliti 20 pasien $(30,6 \%)$ mendapat pengobatan hormonal HCG $2 \times 500 \mathrm{IU} /$ minggu intramuskular selama 5 minggu. Hasil yang didapatkan dari 20 pasien yang diobati HCG, 13 pasien $(65 \%)$ testisnya berhasil turun ke skrotum dan 7 pasien (35\%) gagal. (Tabel 7) Efek samping dari stimulasi HCG berupa pertumbuhan penis, penambahan pigmentasi skrotum, pertumbuhan rambut pubis dan penutupan epipise tulang yang lebih awal apabila dipakai dosis 15.000 IU. Pada penelitian Jobs tahun 1992 dosis HCG stimulasi sel Leydig yang optimal 10.000 IU. Penggunaan intranasal LH-RH di Eropa pada awal terapi didapatkan hasil antara 20-50\%. Pada penelitian randomized clinical trial kombinasi terapi dengan HCG $500 \mathrm{IU} /$ im selama 3 minggu dan intranasal LH-RH 1,2 mg/hari selama 4 minggu dapat menunjukkan penurunan testis $38,5 \%$ dari kasus kriptorkismus. ${ }^{8,18}$ Dikatakan yang paling baik adalah terapi kombinasi antara LHRH dan HCG. ${ }^{8} \mathrm{Ke}-$ untungan terapi hormonal adalah (1). Keberhasilan bervariasi antara $10-80 \%$ sehingga akan mengurangi tindakan operasi. (2). Efek samping tidak ada atau minimal. (3). Lebih menguntungkan pada kriptorkismus bilateral oleh karena operasinya lebih sulit.

Banyak penelitian terapi hormonal pada kriptorkismus dengan hasil yang sangat bervariasi, namun terapi hormonal ini tetap merupakan pilihan utama pengobatan kriptorkismus sebelum dilakukan tindakan bedah. ${ }^{2,16}$ Dengan orchiopexy pada kasus kriptorkismus unilateral dapat memperbaiki fertilitas $30-50 \%$ bila dibandingkan dengan yang tidak dikoreksi. ${ }^{8}$ Penelitian lain mengatakan bahwa keberhasilan orchiopexy $80 \% .{ }^{19}$ Tindakan orchiopexy tidak dapat mencegah tumor ganas testis tetapi dapat dipergunakan sebagai

Tabel 6. Distribusi underscendence testis (UDT) berdasarkan kelainan penyerta

\begin{tabular}{|c|c|c|c|c|c|c|}
\hline \multirow{2}{*}{ Penyakit penyerta } & \multicolumn{3}{|c|}{ UDT } & \multirow{2}{*}{$\begin{array}{l}\text { Testis } \\
\text { retraktil }\end{array}$} & \multirow[t]{2}{*}{ Jumlah } & \multirow[t]{2}{*}{$\%$} \\
\hline & kanan & kiri & bilateral & & & \\
\hline - Tidak ada & 16 & 16 & 9 & 3 & 44 & 69,9 \\
\hline - Mikropenis & 2 & 2 & 2 & 1 & 7 & 11,1 \\
\hline - Sindrom PraderWilli & - & - & 1 & - & 1 & 1,6 \\
\hline $\begin{array}{l}\text { Skrotum bifidum } \\
\text { dengan hipospadia }\end{array}$ & 4 & 3 & - & 1 & 8 & 12,6 \\
\hline - Sindrom Noone & 1 & - & - & - & 1 & 1,6 \\
\hline - Sindrom Kallmann & - & - & 1 & - & 1 & 1,6 \\
\hline - Obesitas & - & 1 & - & - & 1 & 1,6 \\
\hline Jumlah & 23 & 22 & 13 & 5 & 63 & 100 \\
\hline
\end{tabular}

Tabel 7. Hasil terapi hormonal pada kriptorkismus

\begin{tabular}{lccccc}
\hline Terapi hormonal & $\begin{array}{c}\text { Kriptorkismus } \\
\text { inguinal }\end{array}$ & $\begin{array}{c}\text { Kriptorkismus } \\
\text { preskrotal }\end{array}$ & $\begin{array}{c}\text { Testis tak } \\
\text { teraba }\end{array}$ & $\begin{array}{c}\text { Testis } \\
\text { sliding }\end{array}$ & Jumlah \\
\hline Berhasil & 7 & - & 4 & 2 & 13 \\
Tidak berhasil & 2 & 1 & 4 & - & 7 \\
\hline Jumlah & 9 & 1 & 8 & 2 & 20 \\
\hline
\end{tabular}


pemantauan dini adanya tumor testis. ${ }^{17}$ Oleh karena masalah yang sering terjadi pada kriptorkismus adalah keganasan testis, fertilitas yang menurun, torsi testis, dan hernia inguinalis; ${ }^{17}$ Komplikasi yang paling banyak dijumpai pada orchioplexy adalah atropi testis, hal ini terjadi karena terpotongnya pembuluh darah testis, edem pasca operasi, peradangan yang akan menyebabkan iskemik dan atropi testis. Komplikasi yang lain adalah infeksi dan perdarahan. ${ }^{17}$

\section{Kesimpulan dan Saran}

Disimpulkan bahwa pengetahuan dokter anak dan orang tua terhadap kriptorkismus cukup baik sehingga segera merujuk ke Poliklinik Endokrin Anak FKUI - RSCM Jakarta. Akurasi pemeriksaan ultrasonografi sama dengan pemeriksaan dengan perabaan. Separuh dari pasien dapat berhasil diobati dengan HCG. Apabila pengobatan dimulai sejak umur 6 bulan, terwujudnya keberhasilan pengobatan akan lebih tinggi.

Disarankan bahwa,(1). Diagnosis dini kriptorkismus sangat diperlukan dengan melakukan pemeriksaan fisik genitalia yang paripurna. (2) Perlu berhati - hati pada kriptorkismus dengan kelainan penyerta, kriptorkismus bilateral , ambigues genitalia dan kriptorkismus dengan hipospadia. (3) Terapi hormonal dengan injeksi HCG $2 \times 500 \mathrm{IU} /$ minggu selama 5 minggu dapat diberikan pada anak dengan kriptorkismus sejak berumur 6 bulan. (4) Kasus kriptorkismus berumur kurang dari 6 bulan perlu dilakukan observasi, sedangkan apabila umur lebih dari 2 tahun dirujuk ke Bagian Bedah atau pada sliding testis dapat diobati HCG. (5) Pemeriksaan testis dengan perabaan masih sensitif dan apabila tidak teraba dikonfirmasi dengan pemeriksaan USG/ MRI. (6) Kriptorkismus bilateral dilakukan uji HCG, apabila negatif dilanjutkan dengan laparoskopi karena bisa melihat jaringan testis secara langsung. (7) Kriptorkismus yang disertai hipospadia perlu diperiksa kromosom.

\section{Daftar Pustaka}

1. Rukman Y, Darmawan BS. Aspek hormonal pada kriptorkismus. Dalam: Rukman Y, Batubara JRL, Tridjaja $\mathrm{B}$, penyunting. Tatalaksana optimal kriptorkismus. Jakarta: Bagian Ilmu Kesehatan Anak FKUI-RSCM IDAI Jaya: 1994. h. 17-25.

2. Batubara JRL. Terapi hormonal pada kriptorkismus. Dalam: Rukman Y, Batubara JRL, Tridjaja B, penyunting.
Tatalaksana optimal kriptorkismus. Jakarta: Bagian Ilmu Kesehatan Anak FKUI RSCM IDAI Jaya; 1994. h. 37-49.

3. August GP. Hypogonadism and cryptorchidism. Dalam: Current review of pediatric endocrinology. Washington: Serono Symposia; 1993. h. 57-64.

4. Witchel SF. Ambigous genilalia. Dalam: Sperling MA, penyunting. Pediatric endocrinology. second ed. New York: Saunders, 2002. h.111-133.

5. Darmawan BS. Perjalanan alamiah kriptorkismus pada bayi lahir hidup di RSCM hingga usia 9 bulan. Tesis. Peserta Program Studi IKA - FKUI Jakarta: Bagian Ilmu Kesehatan Anak FKUI RSCM, 1997. h. 1-73.

6. Ferrer FA, Mckenna PH. Current approaches to the undescended testicle. Contemporary Pediatrics Arch 2000; 1:1-10.

7. Danou M. Ambigous genitalia, micropenis, hypospadia, and cryptorchidism. Dalam: Lifshitz F, penyunting. Pediatric endocrinology .Edisi ketiga. New York: Marcel Dekker; 1996. h. 281-303.

8. Pielai SB, Besner GE. Pediatric testicular problems. Pediatric Clinics of North America 1998; 45: 1-18.

9. Anonymous. Cryptorchidism (editorial). Medicine 2002; h. 2-11.

10. Himawan S. Segi patologik kriptorkismus. Dalam: Rukman Y, Batubara JRL, Tridjaja B, penyunting. Tata laksana optimal kriptorkismus. Jakarta: Bagian Ilmu Kesehatan Anak FKUI RSCM IDAI Jaya; 1994. h.1-15.

11. Elder JS. Ultrasonography is unnecessary in evaluating boys with a nonpalpable testis. Pediatrics 2002; 110: h. 1-8.

12. Firman K. Peran pencitraan pada kriptorkismus. Dalam: Rukman Y, Batubara JRL, Tridjaja B, penyunting. Tata laksana optimal kriptorkismus. Jakarta: Bagian Ilmu Kesehatan Anak FKUI RSCM IDAI Jaya; 1994. h. 27-36.

13. Jordan GH. Laparoscopic management of the undescended testicle. Urol Clin N Am 2001; 28: h.1-11.

14. Dale S, Howard H, Susan S, Stephen R, Michael Z, Dauglas $C$ at all. Hormonal therapy for the subfertility of cryptorchidism. Dalam: Liestal FH, Liestal, penyunting. Hormone research. 2001: h. 33-7.

15. Roger M, Lahlau N, Chaussain JL. Gonadotropin releasing hormone testing in pediatrics. Dalam: Ranke MB, penyunting. Diagnostics of adolescents. Tubingen: Johann Ambrosius Barth; 1996. h. 346-69.

16. Anonymous. Undescended testicle (Editorial). Finnish Med Soc Duod 2001; 11: h.1-20.

17. Docimo SG. The undescended testicle: diagnosis and management. Am Fam Phy 2000; 62:1-10.

18. Michael F, Ioamus G, Giorgos V, Charissis. thirteen years experience with the combined hormonal therapy of cryptorchidism. Dalam: Liestal FH, Liestal BH, penyunting. Hormone research 2001. h. 33-7.

19. Firdaoessaleh. Peran bedah pada kriptorkismus. Dalam: Rukman Y, Batubara JR, Tridjaja B, penyunting. Tatalaksana optimal kriptorkismus. Jakarta: Bagian Ilmu Kesehatan Anak FKUI-RSCM IDAI Jaya; 1994. h.51-70.

20. Wales JKH, Rogal AD, Wit JM. Abnormal genitalia. Dalam: Color atlas of pediatric endocrinology and growth. London: Mosby Wolfl;. 1996. h. 99-116. 